\title{
Spindle Epithelial Tumor with Thymus-Like Differentiation (Settle): A Distinctive Malignant Thyroid Neoplasm: A Case Report
}

\author{
Nikhil Majethia \\ 201 Ashirwad Plot 71 Sector 28 Vashi Assistant professor JJ Hospital
}

\begin{abstract}
The tumors of intrathyroidal epithelial thymoma are a rare group of thyroid neoplasms.of this, spindle epithelial tumor with thymus like differentiation (SETTLE) has been a rare entity reported only 17 times in English literature. A 34-year-old man had an enlarged thyroid for all of his adult life. Over a period of 12 weeks before hospitalization, the thyroid was noted to enlarge rapidly. Histopathological examination with immunohistochemistrical analysis led to diagnosis of SETTLE
\end{abstract}

\section{Introduction}

The spindle epithelial tumor with thymus-like element (SETTLE) is a very rare neoplasm related to the thyroid of young individuals. In 1991, Chan and Rosai unified the concept of SETTLE when they described 8 neoplasms situated in the neck and thyroid of children and young adults, previously diagnosed as malignant teratoma of the thyroid, thyroid spindle cell tumor with mucous cysts or thyroid thymoma. [1] SETTLE is a distinct low-grade neoplasm, believed to be derived from branchial pouch or thymic remnants, with only 1 case report showing association with epithelium-lined cysts of possible branchial pouch derivation. It belongs to a group of cervical lesions that includes ectopic cervical thymoma, ectopic hamartomatous thymoma and carcinoma with thymus-like element (CASTLE). This tumor is composed predominantly of spindle and epithelioid cells with glandular or ductular structures lined by a mucinous or respiratory epithelium. In spite of indolent growth, SETTLE may give metastases many years after the diagnosis. Therefore, a long-term follow-up is required.[2] We present one case, the first report from our hospital, of a patient who has benign clinical course and tumoral features suggestive of a myoepithelial differentiation. The clinicopathologic features of the case reports in the literature are also reviewed.

\section{Case Report}

A 34-year-old man had an enlarged thyroid for all of his adult life. Over a period of 12 weeks before hospitalization, the thyroid was noted to enlarge rapidly. Eighteen years ago, the patient had bilateral seminoma of the testes treated by bilateral orchidectomy and irradiation to the groin area, and had remained tumor free. Physical examination revealed an enlarged and hard thyroid gland, most notably in the right lobe. There were no palpable lymph nodes. A thyroid scan showed a large cold nodule in the right lobe. Laboratory exams showed normal free-T3 free; free-T4 and TSH levels.

Systemic investigations did not yield significant findings. The fine needle aspiration (FNA) cytological study performed was inconclusive. Therefore, resection of the mass was suggested and partial thyroidectomy performed 2 months later. Neck exploration was performed, revealing that the right lobe of the thyroid was hard and adherent to the right sternothyroid muscle. There was no evidence of nodal metastasis on either side of the neck. The final diagnosis was SETTLE. Despite no other therapy having been performed, at the present moment the patient is alive without evidence of recurrence or metastasis 5 years after the initial treatment.

\section{Material and Methods}

The FNA material was received in physiological solution, processed routinely and stained with Papanicolaou. The surgical specimen was received in $10 \%$ buffered formalin and processed routinely. An immunohisto chemical analysis was performed using formalin-fixed, paraffin-embedded tissue sections.

\section{Results}

Cytological findings: The slide prepared from the FNA revealed a highly cellular aspirate consisting of cohesive or isolated sheets of spindle cells with clusters of polygonal cells with benign features in a background of cyanophilic material which resembles mucin. The spindle cells showed elongated or oval nuclei, finely dispersed chromatin, inconspicuous nucleoli, distinct nuclear membrane and a high nuclear-cytoplasm ratio. There was minimal cellular pleomorphism and neither necrosis nor mitotic figures was observed. (Figure 1)

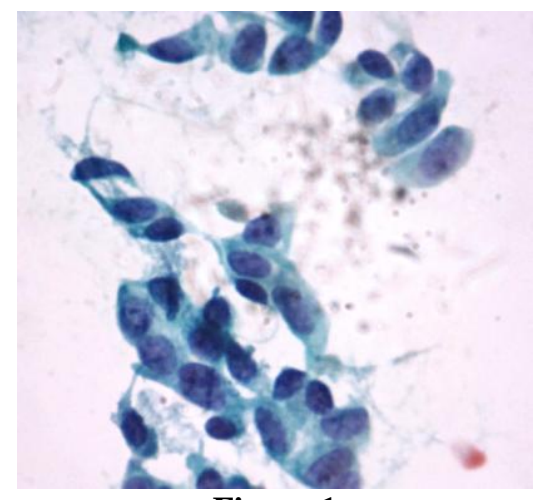

Figure 1 


\section{International Journal of Science and Research (IJSR) \\ ISSN (Online): 2319-7064}

Index Copernicus Value (2013): 6.14 | Impact Factor (2014): 5.611

\section{Pathological Findings}

\section{Macroscopic Features}

The gross examination of the specimen showed a bosselated, well-circumscribed and firm mass, measuring $2.5 \times 2.0 \times 1.8$ $\mathrm{cm}$. The cut surface was solid, grayish brown, slightly lobular with residual thyroid at the periphery. There were focal cysts and mucoid areas. Necrosis, calcifications and haemorrhage were also observed.

\section{Microscopic Features}

Microscopically, the tumor was circumscribed with collagen bands incompletely dividing the tumor in nodules. There was a biphasic pattern composed of a mixture of a predominant component of spindle cells and a minor glandular component with mucinous and respiratory-type epithelium. The mitotic index was low and there were areas with necrosis or hemorrhage. The tumor was highly cellular and formed predominantly by reticulated to compact fascicles of spindle cells with a slightly storiform pattern. The spindle cells displayed scanty eosinophilic cytoplasm and elongated to plump nuclei. The nuclei were minimally pleomorphic with both pointed and blunt ends, distinct nuclear membranes, delicate chromatin and inconspicuous nucleoli. The second component of the tumor consisted mainly of glandular and ductular structures lined by mucinous epithelium and ciliated pseudo-stratified epithelium with occasional goblet cells. These structures varied from large cystic spaces to smaller structures and cell clusters, merging imperceptibly with the spindle cells. These cells displayed a columnar to cuboidal nuclei. Focal areas with squamous epithelium arising abruptly from the spindle cells were observed. There were interstitial mucin pools, intercellular edema and scant lymphocytes. Normal thyroid tissue was observed in the periphery of the mass, and occasional thyroid follicles were found within the tumor. (Figure 2 \& 3) Focal positivity for EMA,(Figue 4) mostly in the glandular component, was observed. Calcitotin was negative.

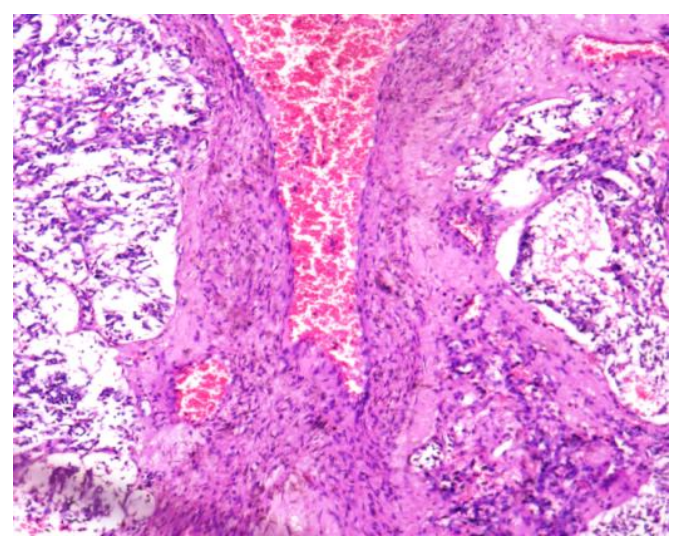

Figure 2

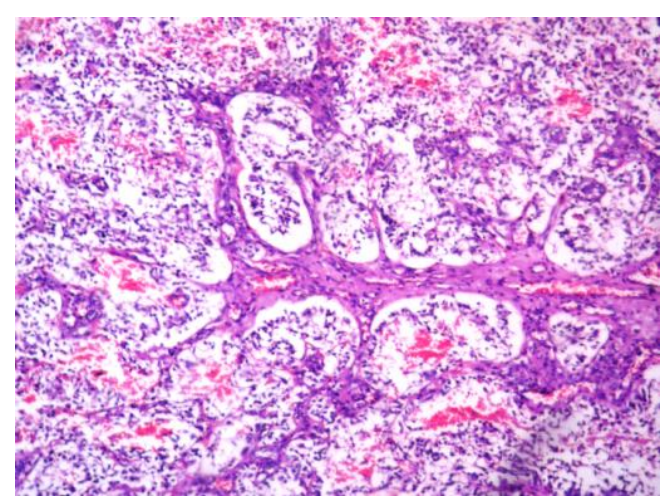

Figure 3

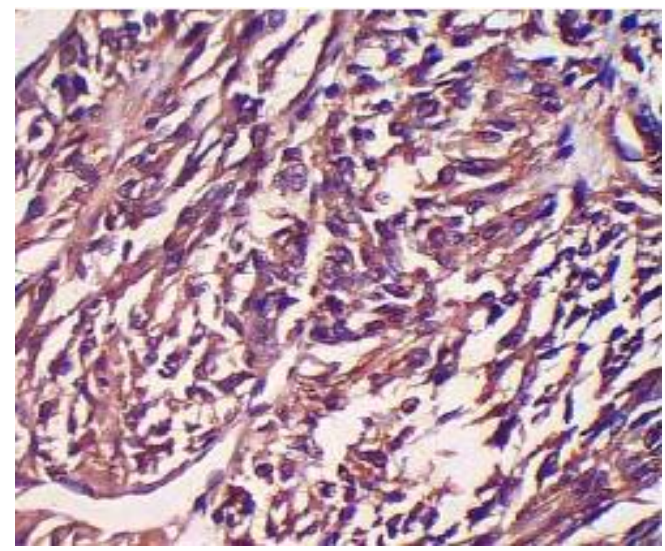

Figure 4

\section{Discussion}

SETTLE, a rare primary tumor of the thyroid, is composed of spindle cells of epithelial nature forming fascicles, merging into glandular structures taking the form of tubules, papillae, and cystic spaces. In some cases, cysts or glands lined by mucinous or respiratory epithelium may be present. Rare cases may be predominantly monophasic, with spindle cell predominance. It has been speculated that SETTLE represents a neoplasm arising from brachial pouch remnants or ectopic thymus, showing possible differentiation towards embryonic thymus (thymoblastoma). [3,4] Up to July 2010, from the available data in the indexed literature, there were 30 case reports of SETTLE. This rare tumor occurs in young and old individuals with a mean age of 17.9 years at presentation (ranging from 2 to 59 years), with a male-tofemale ratio of 1.1 . In this case the patient was 34 years old at the time of diagnosis. The generally initial presentation described is a painless mass, within or around the thyroid. In the literature, there are at least 4 patients who had the thyroid mass noticed for four or more years, which suggest a slow tumoral growth. In spite of the disease progression with metastasis development, low mortality rates are observed, demonstrating the indolent course of the tumor. SETTLE may not produce metastasis until many years after the diagnosis (mean of 11 years) and according to case reports with follow-up information, the overall rate of metastasis is of about $20 \%$, spread is mainly to lung, mediastinum, local lymph node and kidney.Error! Bookmark not defined. 
International Journal of Science and Research (IJSR)

ISSN (Online): 2319-7064

Index Copernicus Value (2013): 6.14 | Impact Factor (2014): 5.611

Diffentiatial diagnosis of SETTLE [5, 6]

\begin{tabular}{|c|c|c|}
\hline Diagnosis & Features & Special stain and IHC \\
\hline Thymoma & $\begin{array}{c}\text { Jigsaw puzzle like lobulation, plump spindle or epithelial cells, which often } \\
\text { presents with lymphocytes }\end{array}$ & $\begin{array}{c}\text { CD20++ } \\
\text { Tdt }+++ \text { thymocytes }\end{array}$ \\
\hline CASTLE & $\begin{array}{c}\text { Malignant tumor resembles thymic carcinoma with lymphoepithelioma like } \\
\text { pattern }\end{array}$ & \\
\hline Teratoma of Thyroid & Mature tissue from all 3 germ layers & \\
\hline $\begin{array}{l}\text { Sarcomatoid } \\
\text { Anaplastic carcinoma }\end{array}$ & $\begin{array}{l}\text { Rapid growth, early metastasis, histologically characterized by overt nuclear } \\
\text { atypia, necrosis cellular pleomorphism, high mitotic index, vascular invasion, } \\
\text { prominent vascularity, giant cells, and wide extrathyroid extension. }\end{array}$ & $\begin{array}{l}\text { Cytokeratin+ } \\
\text { CEA }+ \\
\text { Thyroglobin - }\end{array}$ \\
\hline $\begin{array}{l}\text { Medullary } \\
\text { Carcinoma- Spindle cell } \\
\text { variant }\end{array}$ & $\begin{array}{c}\text { Spindle cells, stippled /sand pepper nuclei, granular cytoplasm fibrovascular } \\
\text { septae lack of glandular pattern }\end{array}$ & $\begin{array}{c}\text { Amyloid++ } \\
\text { Calcitonin }++ \\
\text { Chromogranin }++\end{array}$ \\
\hline Synovial Sarcoma & $\begin{array}{l}\text { Rapid tumor growth, The spindle cells are usually monomorphic, } \\
\text { hyperchromatic, but present a higher mitotic index. The glandular component is } \\
\text { well differentiated, but does not display mucinous or goblet cells. }\end{array}$ & $\begin{array}{l}\text { Patchy cytokeratin +/- } \\
\text { CD99++ } \\
\text { BCL-2++ }\end{array}$ \\
\hline $\begin{array}{l}\text { Ectopic hamartomatous } \\
\text { thymoma( Branchial } \\
\text { Analage Mixed Tumor) }\end{array}$ & $\begin{array}{c}\text { Plump spindle cells, delicate fibroblast-like spindled cells, mature } \\
\text { adipose tissue, and epithelial elements with squamous, glandular or } \\
\text { indeterminate morphology. }\end{array}$ & \\
\hline SETTLE & $\begin{array}{l}\text { biphasic pattern composed of a predominant } \\
\text { component of spindle cells and a minor glandular mucous } \\
\text { component, occasionally cystic and collagen stripes }\end{array}$ & $\begin{array}{c}\text { Congo red - } \\
\text { Actin+ } \\
\text { Cytokeratin+++ } \\
\text { Calcitonin- } \\
\text { NSE- }\end{array}$ \\
\hline
\end{tabular}

\section{Conclusion}

In conclusion, this case report showed the first report from our hospital and the possibility of a myofibroblastic differentiation. The SETTLE is among four tumors related to the thyroid, easily differentiated by clinicpathologic correlation. It is a low-grade malignant neoplasm, with epithelial differentiation confirmed by immunohistochemical. Despite all the descriptions in the literature, this tumor remains with uncertain histogenesis and lacking convincing proof of thymic differentiation or branchial pouch derivation. SETTLE can metastasize a long time after the surgical resection. Because of this, the patients need long-term follow-up, with particular attention to monitoring the lungs.

\section{Acknowledgement}

Metropolis Healthcare Lab, Kurla, Mumbai.

\section{References}

[1] Ashu Rastogi, Uma Nahar Saikia, Ashok Kumar Gupta, Anil Bhansali, Recurrent Thyroid Nodule: Spindle Epithelial Tumor with Thymus Like Differentiation(SETTLE). Indian Pediatrics. Vol 49. June $16: 2012 ; 482-484$.

[2] Luiz Antônio Magnata Filho, Maria Alice Neves Bordallo, Cencita H. C. N. Pessoa, Rossana Corbo, Daniel Alves Bulzico, Fernando Luiz Dias, Avelino L. Machado, Andréia B. Soares, Sima Ferman. Thyroid spindle epithelial tumor with thymus-like differentiation (SETTLE): case report and review. Arq Bras Endocrinol Metab. 2010;54/7.

[3] Wah Cheuk, M.D., Avram A. Jacobson, M.D., John K. C. Chan, M.D. Spindle Epithelial Tumor with ThymusLike Differentiation (SETTLE): A Distinctive Malignant
Thyroid Neoplasm with Significant Metastatic Potential. Mod Pathol 2000;13(10):1150-1155.

[4] Chan JK, Rosai J. Tumors of the neck showing thymic or related branchial pouch differentiation: a unifying concept. Hum Pathol 1991;22:349-67

[5] Chetty R, Goetsch S, Nayler S, Cooper K. Spindle epithelial tumour with thymus-like element (SETTLE): the predominantly monophasic variant. Histopathology 1998;33:71-4.

[6] Abrosimov A Y, LiVolsi VA. Spindle Epithelial Tumor with thymus like differentiation (SETTLE) of the thyroid with neck lymph node metastasis: A case report. Endocrine pathol 2005;16(2):130-43. 